\title{
Tensile properties of woven carbon/kevlar reinforced epoxy hybrid composite
}

\begin{abstract}
Carbon fibres and Kevlar fibres are among the commonly used fibres in the composite industry. As carbon fibres usually known for its superior strength, its low impact resistance limited its application in the industry. However, further research found that combining the high strength fibres with more ductile fibres like Kevlar could improve the material's impact resistance. This hybrid effect was also found to be most effective by using intra-ply woven hybrid fibres in the composite. In this work, hybrid composite material was fabricated by using woven carbon-Kevlar cloths with epoxy matrix and the mechanical properties are determined at $0^{\circ}, 45^{\circ}$ and $90^{\circ}$. The hybrid composite material was found to have highest tensile strength at $0^{\circ}$ (carbon) direction. As the material's strength and tensile behaviour are different at every fibre types, the selection of fibre direction of the woven cloth in loading is an important criteria in any applications.
\end{abstract}

Keyword: Carbon fibres; Composite materials; Epoxy resin; Kevlar fibres; Tensile strength 